\title{
Overlapping cardiac volume reduction operation
}

Yoshiro Matsui, MD, ${ }^{a}$ Yasuhisa Fukada, MD, ${ }^{\text {a }}$ Yukio Suto, MD, ${ }^{b}$ Hidetoshi Yamauchi, MD, ${ }^{\text {b }}$ Bin Luo, MD, ${ }^{\text {b }}$ Masatoshi Miyama, MD, ${ }^{\text {b }}$ Shigeyuki Sasaki, MD, ${ }^{\mathrm{c}}$ Tatsuzo Tanabe, MD, ${ }^{\mathrm{a}}$ and Keishu Yasuda, MD, Sapporo and Ishikari-Tobetsu, Japan

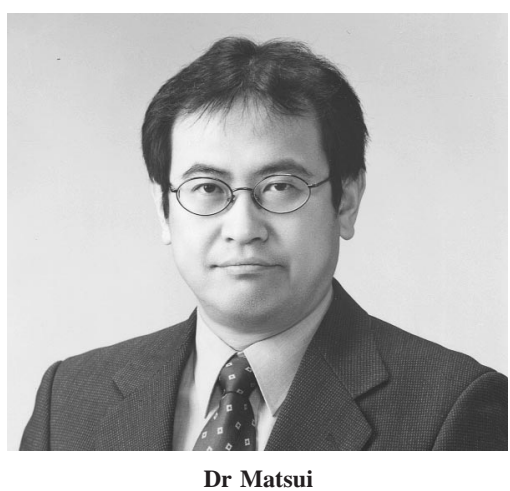

$\mathrm{P}$ artial left ventriculectomy (PLV) has been introduced to treat end-stage cardiomyopathy but has not achieved a favorable outcome. We thought it important to preserve cardiac muscle possessing the potential power source of the left ventricle and to avoid resection of the left circumflex coronary artery. From this viewpoint, we developed a new operative procedure of left ventricular (LV) volume reduction without any resection of cardiac muscle and have confirmed its beneficial effect in a canine model. This is the first clinical report of this new procedure.

\section{Clinical Summary}

A 62-year-old man with dilated cardiomyopathy (DCM) was referred to our institution in August 2001. Since 1995, he has been treated with medication, including $\beta$-blockers, for DCM with mild mitral and aortic regurgitation confirmed by endocardial biopsy. However, he had orthopnea (New York Heart Association class III) in May 2001, when echocardiography demonstrated an ejection fraction (EF) of 23\% with severe mitral and moderate aortic and tricuspid regurgitation. In July 2001, he required direct-current shock to be resuscitated from an arrhythmia. Preoperative catheter laboratory study showed mean pulmonary wedge pressure of 12 $\mathrm{mm} \mathrm{Hg}, \mathrm{LV}$ end-diastolic pressure of $18 \mathrm{~mm} \mathrm{Hg}$, cardiac index of $1.86 \mathrm{~L} \cdot \mathrm{min}^{-1} \cdot \mathrm{m}^{-2}, \mathrm{LV}$ end-diastolic volume of $182 \mathrm{~mL}, \mathrm{LV}$ end-systolic volume of $137 \mathrm{~mL}, \mathrm{EF}$ of $24 \%$, and intact coronary arteries.

From the Department of Cardiovascular Surgery, NTT East Corporation Sapporo Hospital, ${ }^{\mathrm{a}}$ Sapporo, the Department of Cardiovascular Surgery, Hokkaido University School of Medicine, ${ }^{\text {b }}$ Sapporo, and the Division of Medical Sciences, Health Science University of Hokkaido, ${ }^{\mathrm{c}}$ Ishikari-Tobetsu, Japan.

Received for publication Dec 12, 2001; accepted for publication Feb 5, 2001

Address for reprints: Yoshiro Matsui, MD, NTT East Corporation Sapporo Hospital, Department of Cardiovascular Surgery, S1W15 Chu-ku, Sapporo, Japan (E-mail: yoshirou_matsui@ hokkaido.east.ntt.co.jp).

J Thorac Cardiovasc Surg 2002;124:395-7

Copyright $(9) 2002$ by The American Association for Thoracic Surgery

$0022-5223 / 2002 \$ 35.00+0 \quad \mathbf{1 2 / 5 4 / 1 2 3 6 1 6}$

doi: $10.1067 / \mathrm{mtc} .2002 .123616$
The operation was performed on August 4. Informed consent was obtained before the operation. The operative procedure included replacement of the thickened aortic valve with myxoid change with a 21 Carpentier-Edwards pericardial valve, annuloplasty of a simply dilated mitral anulus with a 26 Carpentier Physioring, tricuspid annuloplasty with a 30 Cosgrove ring (Baxter Healthcare Corporation, Irvine, Calf), and our original LV reduction operation, termed overlapping cardiac volume reduction operation (OLCVR). OLCVR consisted of the following 3 steps: (1) a transmural longitudinal incision along the left anterior descending artery in the enlarged LV free wall; (2) continuous sutures of the left incision marginal to the endocardium of the septal wall; and (3) interrupted sutures of the right incision marginal to the ventricular free wall (Figures 1 and 2). It took about 30 minutes to complete the OLCVR procedure. Cardiopulmonary bypass was conducted under mild hypothermia with antegrade and retrograde intermittent cold blood cardioplegia. Weaning from cardiopulmonary bypass was easy after a 121-minute crossclamping period.

\section{Results}

The patient recovered uneventfully and was extubated 4 hours after the operation. Two weeks' postoperative catheter study showed mean pulmonary wedge pressure of $7 \mathrm{~mm} \mathrm{Hg}$, cardiac index of $2.93 \mathrm{~L} \cdot \mathrm{min}^{-1} \cdot \mathrm{m}^{-2}, \mathrm{LV}$ end-diastolic volume of $141 \mathrm{~mL}$, LV end-systolic volume of $87 \mathrm{~mL}$, and $\mathrm{EF}$ of $38 \%$ without damage to coronary arteries. He was discharged 26 days after the operation and has been doing well in New York Heart Association class I for 7 months without any troublesome arrhythmias.

\section{Discussion}

The primary objective of PLV is to decrease LV wall tension on the basis of Laplace's law ${ }^{1}$ under the premise that remaining cardiac muscle is viable. However, prediction of the viability of cardiac muscle is often difficult, and PLV would worsen LV function if the resected area included the most viable muscles. ${ }^{2}$ Another problem is that PLV is associated with the resection of the obtuse marginal circumflex coronary artery, which might lead to myocardial ischemia, causing postoperative arrhythmia. ${ }^{4}$ Recent series of PLV have shown a high operative mortality, high incidence of recurrence of heart failure, and arrhythmia-related deaths. $^{3}$ 

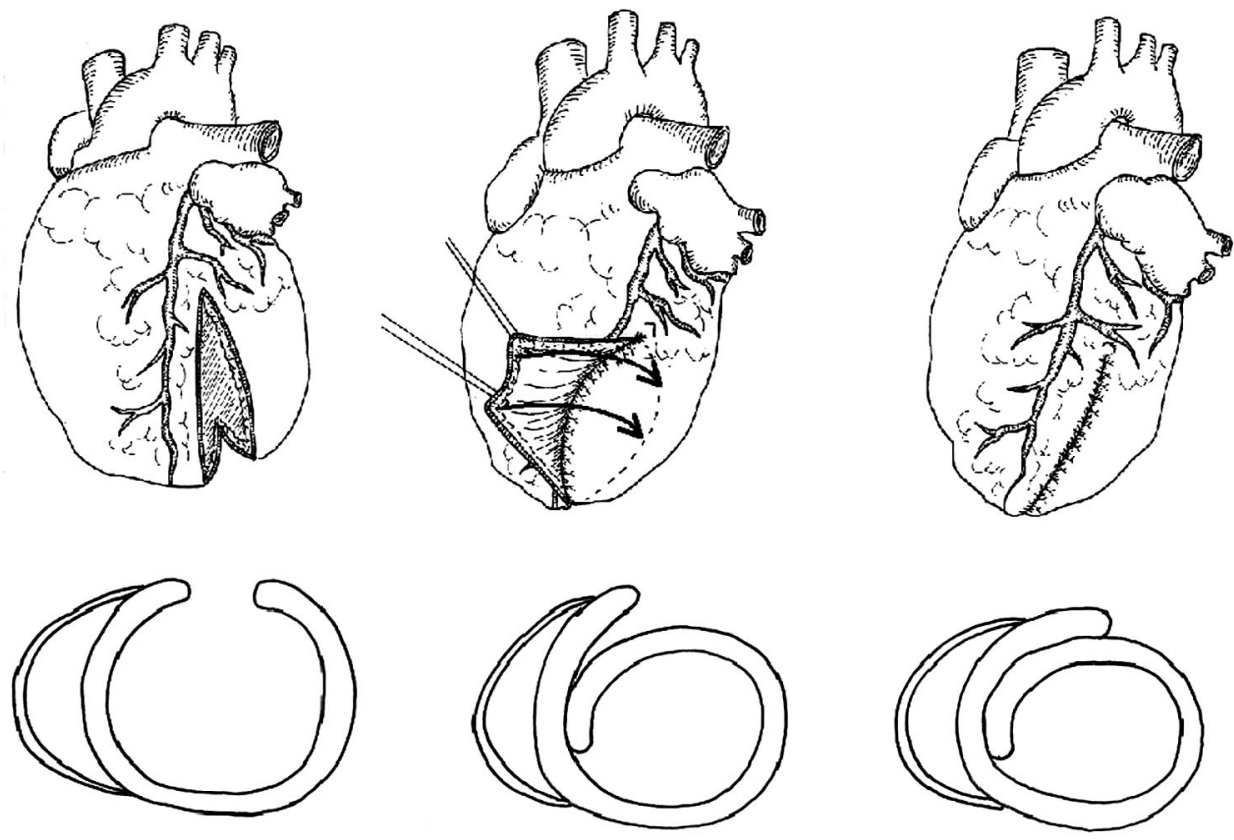

Figure 1. Operative procedures of OLCVR. Left, A transmural longitudinal incision along with the left anterior descending branch in the enlarged LV free wall. Middle, Continuous sutures of the left incision marginal to the endocardium of the septal wall. Right, Interrupted sutures of the right incision marginal to the LV free wall.
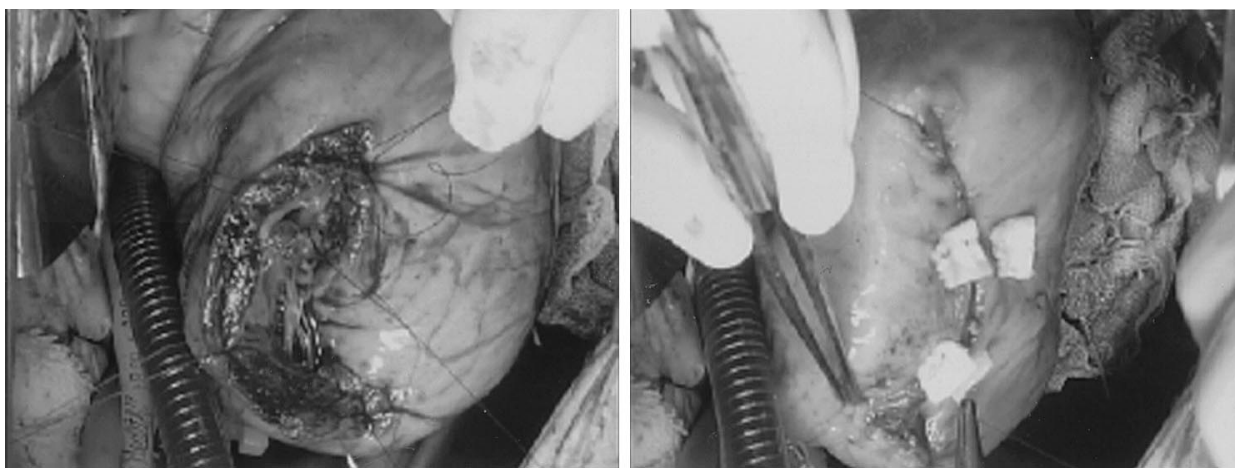

Figure 2. Intraoperative view of OLCVR. Left, Continuous sutures of the left incision marginal to the septal wall. Right, Pledget-supported mattress sutures of the right incision marginal which vessels were cauterized electrically to the LV free wall.

Our new procedure, OLCVR, has a couple of merits when compared with the traditional PLV, namely preservation of cardiac muscle and preservation of the circumflex coronary artery. These merits might be better suited to preserve LV contractility and to avoid LV ischemia than PLV, which might lead to a better outcome. The other presumable merits might include that (1) OLCVR might be a reversible procedure when the overlapping portion is too excessive; (2) the overlapping portion of cardiac muscle might have a girdling effect in the long-term period, as well as during cardiomyoplasty ${ }^{4}$; and (3) the excluded portion (a part of septum and anterior muscle) does not undergo direct pressure from the inside of the heart and therefore might possess a potential ability to support cardiac function, as well as cardiomyoplasty with the latissimus dorsi. ${ }^{5}$

Because we performed aortic, mitral, and tricuspid valve surgery in addition to OLCVR, the drastic improvement of the patient's condition might not result from OLCVR only. However, mitral reconstruction would be beneficial for patients with DCM and viable myocardium but without severely deteriorated LV function. ${ }^{1}$ According to preoperative deteriorated LV functions, OLCVR must be beneficial for the rapid recovery of cardiac function and might save medical expenses in our case. Although long-term follow-up is mandatory, OLCVR might become a therapeutic option for end-stage cardiomyopathy. 


\section{References}

1. Dowling RD, Koenig SC, Ewert DL, Laureano MA, Gray LA. Acute cardiovascular changes of partial left ventriculectomy without mitral vavle repair. Ann Thorac Surg. 1999;67:1470-2

2. Suma H, Isomura T, Horii T, Sato T, Kikuchi N, Iwahashi K, et al. Nontransplant cardiac surgery for end-stage cardiomyopathy. J Thorac Cardiovasc Surg. 2000;119:1233-45.
3. Redmann K, Lunkenheimer PP, Dietl KH, Cryer CW, Batista RJ, Anderson RH. Immediate effects of partial left ventriculectomy on left ventricle function. J Card Surg. 1998;13:453-62.

4. Capouya ER, Gerber RS, Drinkwater DC Jr, Pearl JM, Sack JB, Aharon AS, et al. Girdling effect of nonstimulated cardiomyoplasty on left ventricular function. Ann Thorac Surg. 1993;56:867-71.

5. Matsui Y, Yamauchi H, Suto Y, Dudra J, Gou M, Yasuda K. Effects of dynamic cardiomyoplasty on left ventricular systolic and diastolic performance in an acute canine model. Surg Today. 1998;28:1154-9. 